\title{
EXPERIMENTAL STUDY TO COMPARE FACTORS INFLUENCING EXIT CHOICE BEHAVIOUR IN EMERGENCY EVACUATION SITUATIONS USING VIRTUAL REALITY TECHNIQUES
}

\author{
S. Singh ${ }^{1 *}$, M. Saberi ${ }^{2}$ \\ ${ }^{1}$ Department of Civil Engineering, Monash University Clayton, Australia - singh_sunny@outlook.com \\ ${ }^{2}$ School of Civil and Environmental Engineering, University of New South Wales Sydney, Australia - meead.saberi@unsw.edu.au
}

Commission IV

KEY WORDS: Virtual Reality, Emergency Evacuation, Herding, Crowding, Exit Familiarity

\begin{abstract}
:
Successful emergency evacuation of a large crowd depends on understanding human behaviour and its interaction with environmental stimuli in that situation. A careful study of human behaviour in these stressful and often time-bound situations can enable building designers to account for these effects to develop the most efficient evacuation strategies. One of the major roadblocks of the field has been the lack of reliable data collection techniques. Traditionally, most of the data analysed for these studies is either collected from historical events or through stated preference (SP) surveys given the challenges of conducting high-risk emergency evacuation experiments. The project is aimed at conducting emergency evacuation scenarios in a virtual reality (VR) environment. Eighty-four participants participated in multiple cases as a part of three VR scenarios to test various factors affecting their decision-making process. Participants were immersed in VR scenarios and subjected to a series of choices. Incorporation of VR technology enabled the experiment to record participants' stated preference with a much greater degree of certainty and realism as opposed to traditional pen and paper methods. The study devised a discrete choice model and calibrated it using the data obtained from the VR-based survey. When testing multiple competing factors in the VR scenarios and comparing the results with previous studies, in one VR scenario, the direction of exit signs was found more influential than crowding. In another scenario, familiarity with an exit appeared to be more influential than herding behaviour and exit distance. Overall, the VR technology is demonstrated to provide an advantage as a means to collect data and has come out as a promising tool to be incorporated in future emergency exit choice studies.
\end{abstract}

\section{INTRODUCTION}

With the increasing population, skyscrapers' height has gone up significantly as a growing number of towns are being converted into concrete jungles. In an emergency, a robust emergency escape system is required to help evacuees escape safely and quickly before the infrastructure incurs substantial damage. Various experiments have been conducted to understand human behaviour in an emergency, but most of them failed to paint an accurate picture of reality (Gwynne et al., 1999; Olivier et al., 2014) because of their inability to recreate the emergency scenario without subjecting participants to considerable risk. Virtual Reality (VR) apparatus allows us to use immersive technology to recreate emergency scenarios accurately and generate the same emotions in participants eliminating the risks involved at the same time.

\subsection{Decision Making}

The process of decision making has widely been categorised into three hierarchal steps: 1) Strategizing or making the choice of moving to a safe place; 2) Tactics or choosing between different routes and exits; 3) Operation or making short term choice on the move to recalibrate strategy based on interaction with the environment (Lovreglio, Ronchi, \& Nilsson, 2015; Lovreglio et al., 2014). The choice of the exit route is crucial to the effectiveness of the evacuation process. The exit route selection process includes a series of local and global choices (Ronchi, Nilsson, \& Gwynne, 2012). Choices of evacuees are driven by a global exit motive which is further broken down into local choices. A series of local choices might drive the global aim of evacuation as every time a local choice is eliminated, several global exits associated are also eliminated. This project aims to compare environmental and social factors that influence the local choice to ascertain their relative importance using VR. Several factors like distance from exits, crowding at exits, herding behaviour, familiarity with exits, etc. will be tested through experimentation.

Studies in the past have put forward several theories to elaborate aspects of evacuees' behaviour (Tong \& Canter, 1985), the affiliative case when followers follow the decision-maker (Sime, 1985), the social argument theory where evacuees argue based on available information to prevent decision-maker from making a negative judgement (Nilsson \& Johansson, 2009), social proof where decision maker follows evacuees' who have already made a decision (Cialdini, 1993), etc. The familiarity with an exit can be highly influential in affecting the decision (Fahy, Proulx, \& Aiman, 2012).

Building evacuation models are widely designed with an assumption that evacuees will follow the proposed evacuation route. However, when evacuee fails to follow directional signage, it becomes crucial to understand the influence of other factors around them. (Haghani \& Sarvi, 2017) presented research wherein at large venues such as a major transport station, evacuees' movements were modelled based on stated preference (SP) surveys and revealed preference (RP) experiments. The researchers noted a level of perceived bias in the top-down view in the SP surveys. Furthermore, there was a greater degree of

\footnotetext{
* Corresponding author
} 
randomness in the RP data that was unaccounted for in the SP survey models. The researchers suggested enhancing the realism of the SP surveys would improve the accuracy of the collected data and estimated models. Adding a VR environment on top of the survey may help participants realise the situation better and provide more realistic than idealist responses. For this study, the following terms play a crucial role throughout.

\subsection{Herding Behaviour}

Herding Behaviour $(\mathrm{HB})$ is a type of crowd interaction identified as an influencing factor. HB is exhibited by evacuees following others in front of them instead of searching for the most efficient evacuation route themselves. This belief that other people are moving towards the best exit may be misguided and is not well accounted for in software packages that estimate large buildings' safe egress time.

\subsection{Exit Familiarity}

Exit Familiarity (EF) is a state of evacuee's awareness of the place that they are about to exit and the surroundings that each (or some) exit leads up to. Specific to the study, the effects of participants' familiarity with one exit out of the options available have been studied.

\subsection{Crowding}

Crowding is a state where an exit is at capacity and evacuees incur wait time before crossing the exit. It is different from herding in a way that the decision-maker is focused on the exit rather than other evacuees. A bottleneck situation created at the exits creates congestion in the outflow and evacuees must wait for passage to be cleared before leaving through the exit.

\section{LITERATURE REVIEW}

Human behaviour during stressful situations is highly intricate. Several models have been developed in the past to understand the mechanics of the human decision-making process (Kuligowski, Peacock, \& Hoskins, 2010). Some models focus on the distance from the exit and overlook all other factors, while there are models where evacuee looks for the best choice out of available options based on some specific criterion (Heliövaara et al., 2012). Utility Models developed by (Ben-Akiva \& Lerman, 1985) could be used to predict choices at an individual level and allow the uncertainty to be included in the model. Some researchers have incorporated evacuee characteristics into the model for a further advantage (Greene, 2000). These studies define decision-making framework based on those Random Utility Models to determine short-range and long-range behaviour (Hoogendoorn \& Bovy, 2004).

\subsection{Virtual Reality}

VR has found its use in multiple fields. It is used to distract patients through the painful chemotherapy sessions (Rauterberg, 2004), treat patients with fear psychosis, etc. The immersion aspect of VR is considered one of the essential features of the technology (Bhatt, 2004). It allows the participant to enter a psychological state where they get immersed into the activity to the level that the experience feels real. (Riva, et al., 2007) found that natural human emotions were far better experienced in a virtual environment when compared with a questionnaire survey. These prospects of VR make it an ideal tool to understand human psychology behind exit choice selection. Some research has been done using VR on exit choice behaviour (Kinateder et al., 2014).
In their paper "Responding to a fire emergency in a virtual environment: different patterns of action for different situations", (Gamberini et al., 2010) found that when immersed in VR, participants acted as they would in a real-life scenario. Their reactions were genuine, as they recognised the dangerous aspects of the scenario they were placed in. The results of other experiments have determined that in VR, a participant's psychology, behaviour, and emotions were equivalent to what they would otherwise have experienced in a real-world experiment (Kinateder et al., 2014). It also revealed that conflicting information had an enormous impact on the premovement time. The exits' location was also influential in deciding the amount of time taken by the participant before moving.

\subsection{Effects of Familiarity with Exits on Exit Choice}

Extensive research has been done on the relationship between people and their environment to determine the exit choice decision-making factors. In August 1973, a burning cigarette triggered a disastrous fire at the Summerland Leisure Centre on the Isle of Man. The Summerland Fire Commission (SFC) Report of May 1974 reported, "Of an estimated 3,000 people in the building at the time, the vast majority escaped amidst scenes of panic, but 50 persons - men, women, and children - perished". (Sime, 1983) studied 500 accounts of fire collected from survivors shortly after the fire. His analysis revealed that most occupants evacuated through familiar exits or had followed familiar people (family members or friends) in exiting the building. Many occupants ignored nearby exit routes, which were less crowded and closer. Sime's results revealed a strong influence of 'affiliative' behaviour and exit familiarity on exit choice.

This factor has since been a predominant observation in nightclub fires. The most notable nightclub fire confirming this behaviour was in 2003 in Warwick, Rhode Island, when illegal pyrotechnics display ignited plastic foam used as sound insulation in walls and ceilings at Station Nightclub. One hundred people were killed, and over 200 were injured. Of the 462 people in attendance, $66 \%$ ignored nearby exits and attempted to evacuate from the main entrance.

\subsection{Effects of Signage on Exit Choice}

In (Lovreglio, Ronchi, \& Nilsson, 2016), an experiment was carried out where people had to choose between the stairs or a fire evacuation approved elevator. A higher proportion of participants chose the elevators as the first evacuation route in the flashing light scenario compared with the no flashing light scenario. Interestingly only 1 of the 20 participants in the scenario with the flashing light acknowledged noticing the light. This suggests that people are unlikely to notice unfamiliar fire evacuation signage but are likely to be influenced by them. Slightly more than half of the participants in the no flashing light scenario choose the evacuation elevator compared with $90 \%$ in the flashing light scenario. The mixed logit model studying the effect of signage during evacuation by (Olander et al., 2017) concluded that factors like the standards to which signs are built, the colour of their surroundings, etc. improve the probability of the exit sign being perceived correctly.

\subsection{Effect of Herding on exit choice}

When unprepared, people tend to also 'follow the crowd' which (Cialdini, 1993) refers to as 'social influence'. Previously in 1968, in an experiment conducted by (Darley \& Latane, 1968), 
subjects were tested for the time they take to report an emergency after the smoke had filled the room that they were in. When subjects were in the room with other people, $12 \%$ of them reported an emergency. In contrast, when they were in the room alone, $75 \%$ of subjects had reported the emergency within the first 4 minutes. This experiment signifies the impact of social influence on decision making. (Darley \& Latane, 1968) propose that social influence was the result of wanting 'to fit in' with their peers. (Cialdini, 1993) suggest that in other cases, it is the result of people identifying it as the 'normal' behaviour in that instance.

Research involving HB in exit sign choice was carried out by (Lovreglio et al., 2014). The main decision that evacuees had to make was choosing between the least crowded exit and the most crowded exit. It was found that $\mathrm{HB}$ was much more pronounced when the evacuees were under panic conditions. The model developed suggested that $\mathrm{HB}$ was affected by various environmental and personal factors.

\subsection{Effects of Crowding on Exit Choice}

In a study on crowd behaviour under stressful situations (Moussa1d, et al., 2016), a group that earlier could make smart evacuation decisions broke down into haphazard movements when put under a high-pressure emergency situation. Crowding creates a negative affinity towards an exit choice amongst the evacuee. Generally, the more significant the difference between the number of evacuees crowding two exit options, the evacuee is more likely to choose the other exit (Lovreglio et al., 2014).

In a study on high-stress crowding behaviour, under high stress, the crowd density level reached values up to 5 people per $\mathrm{m}^{2}$, which violated all safety standards and was close to the critical threshold of crowd turbulence (Helbing, Johansson, \& AlAbideen, 2007). The most dangerous zones with the highest density levels were (i) areas in which a decision needed to be made, (ii) areas surrounding the exit where bottlenecks occurred and caused congestion, and (iii) dead ends where the flow of people returning after exploring a wrong option encountered the flow of those moving in the opposite direction (Moussard, et al., 2016). Through the study, various exit choice influencing factors would be tested in a VR environment to reveal observations about an emergency exit situation's mechanics.

\section{METHODOLOGY}

The study focuses on using Random Utility Models (RUMs), a distinct class of Discrete Choice Models (DCMs), as the participants were presented with a finite set of exit options. There are different ways to use RUMs (Lovreglio et al., 2014). Further details on DCM is provided in section 4.1. In the study, three steps identified by (Dell'Olio, Ibeas, \& Cecin, 2011) were used: Background, Survey Design, and Data Collection and Modelling. After a brief literature review to identify the techniques to choose influencing factors, scenarios with the factors to be tested were designed. Second, the framework of the questions for participants was developed in the form of a questionnaire. The information collected in this step was used to develop models in later stages. Later in the process, effective ways to communicate the questions to participants while they had VR gear were devised. For modelling, the collected data was transferred to excel sheets in easy-to-process binary form to be fed into BIOGEME scripts for RUM models. Due to resource constraints and the complexity of designing scenarios, only two to three factors were compared in each scenario. Next, 3D footage was collected for scenarios. A brief description of the sites and scenarios is provided below:

\subsection{Scenarios:}

3.1.1 Scenario 1: Familiarity, herding, and exit distance were the three factors of choice tested over 12 cases. A summary of cases is provided in Table 1 and Figure 1. In the table, Familiarity with 'Exit 1' indicates that the participant virtually entered the room through Exit 1 before scenario cases started. The distance field indicates participants' distance relative to both doors. The herding field indicates the number of other people participant could see exiting from the specified exit. In cases that involved testing the effect of herding behaviour on exit choice, the herd began their exit from behind the participant, walked at a moderate pace towards the exit door, and departed the room, allowing the door too natural close shut behind them. Both exit doors were shut when the participant was asked to decide.

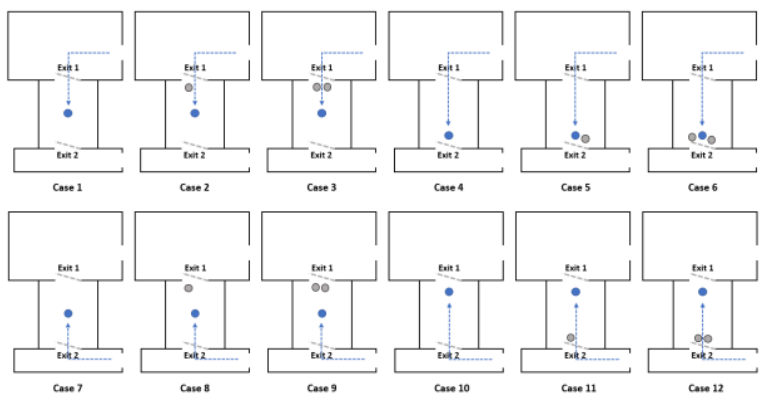

Figure 1. Case setup for scenario 1

\begin{tabular}{|c|c|c|c|}
\hline Case & Familiar Exit & Herding & Exit Distance \\
\hline 1 & Exit 1 & None & Equal \\
2 & Exit 1 & Exit 1 (1) & Equal \\
3 & Exit 1 & Exit 1 (2) & Equal \\
4 & Exit 1 & None & Exit 2 closer \\
5 & Exit 1 & Exit 2 (1) & Exit 2 closer \\
6 & Exit 1 & Exit 2 (2) & Exit 2 closer \\
7 & Exit 2 & None & Equal \\
8 & Exit 2 & Exit 1 (1) & Equal \\
9 & Exit 2 & Exit 1 (2) & Equal \\
10 & Exit 2 & None & Exit 1 closer \\
11 & Exit 2 & Exit 2(1) & Exit 1 closer \\
12 & Exit 2 & Exit 2 (2) & Exit 1 closer \\
\hline
\end{tabular}

Table 1. Case setup for scenario 1

3.1.2 Scenario 2: Exit signage and herding were the two factors of choice tested over 11 cases. For the first factor (direction of exit signs), exit signs made according to AS 2293.1 were installed at the end of the corridor. The signs varied from pointing left, pointing right, or no direction. The second factor was the influence of the herding effect. The participants would see people standing an exit in each case, agreeing or disagreeing with the exit sign.

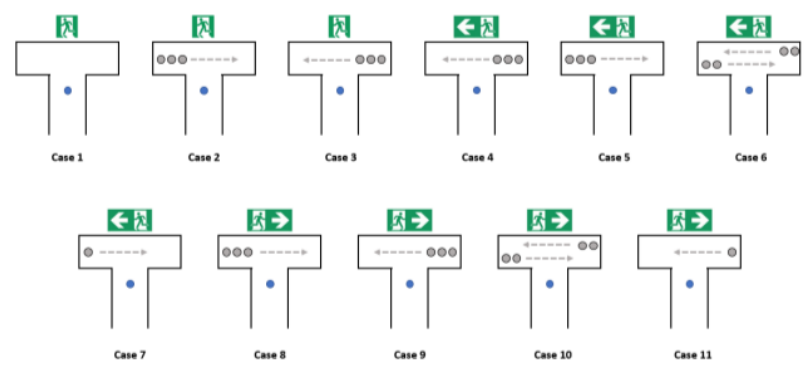

Figure 2. Case setup for scenario 2 


\begin{tabular}{|c|c|c|c|}
\hline Case & Sign Direction & $\begin{array}{c}\text { Crowd to } \\
\text { Left }\end{array}$ & $\begin{array}{c}\text { Crowd to } \\
\text { Right }\end{array}$ \\
\hline 1 & No direction & 0 & 0 \\
2 & No direction & 0 & 3 \\
3 & No direction & 3 & 0 \\
4 & Left & 3 & 0 \\
5 & Left & 0 & 3 \\
6 & Left & 2 & 2 \\
7 & Left & 0 & 1 \\
8 & Right & 3 & 0 \\
9 & Right & 0 & 3 \\
10 & Right & 2 & 2 \\
11 & Right & 1 & 0 \\
\hline
\end{tabular}

Table 2. Case setup for scenario 2

3.1.3 Scenario 3: The physical stress and the blockage of an exit were two factors that were tested in this scenario. The participants were given a choice between having to climb a flight of stairs instead of having to walk around obstacles blocking the other exit. A total of 8 cases were set up to test a combination of these factors. Participants were given time to familiarise themselves with the surroundings once they had put on the VR gear.

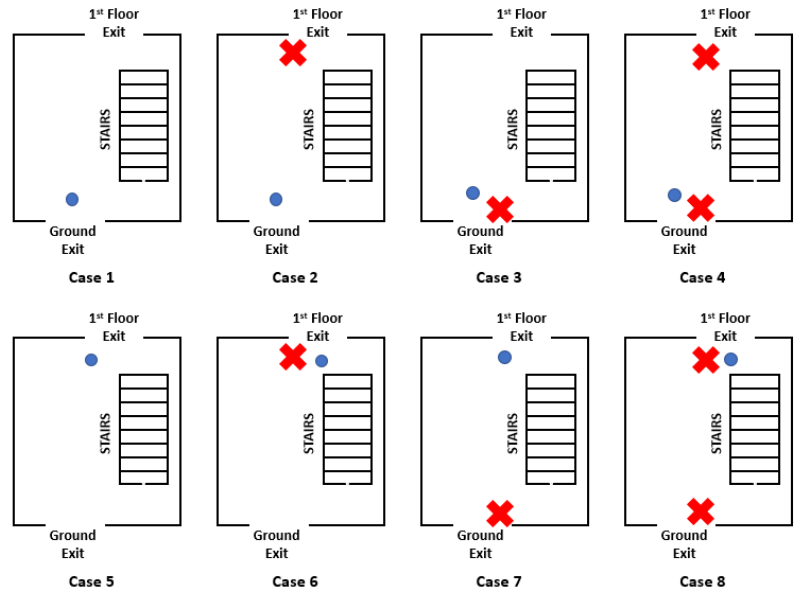

Figure 3. Case setup for scenario 3

\begin{tabular}{|c|c|c|c|}
\hline Case & Starting Position & Ground Exit & Level 1 Exit \\
\hline 1 & Ground & Unblocked & Unblocked \\
2 & Ground & Unblocked & Blocked \\
3 & Ground & Blocked & Unblocked \\
4 & Ground & Blocked & Blocked \\
5 & Level 1 & Unblocked & Unblocked \\
6 & Level 1 & Unblocked & Blocked \\
7 & Level 1 & Blocked & Unblocked \\
8 & Level 1 & Blocked & Blocked \\
\hline
\end{tabular}

Table 3. Case setup for scenario 3

\subsection{Equipment}

The Samsung Oculus Rift VR headset was used as the display to immerse participants into the VR environment. The virtual reality headset display had a resolution of 2,560 x 1,440 pixels with a refresh rate of $60 \mathrm{~Hz}$, and a 96-degree field of view. The Samsung Gear 360-degree camera was used to record the scenarios. Scenarios were recorded by video at $175 \mathrm{~cm}$ (the average height of males in Australia).
Below are a few examples of still shots from videos recorded.

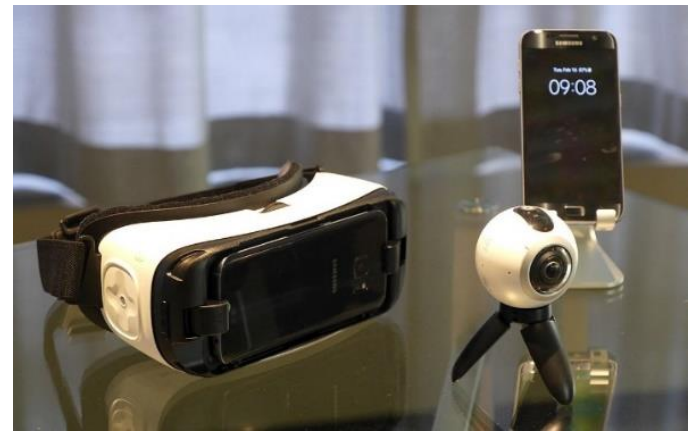

Figure 4. Equipment used for the research

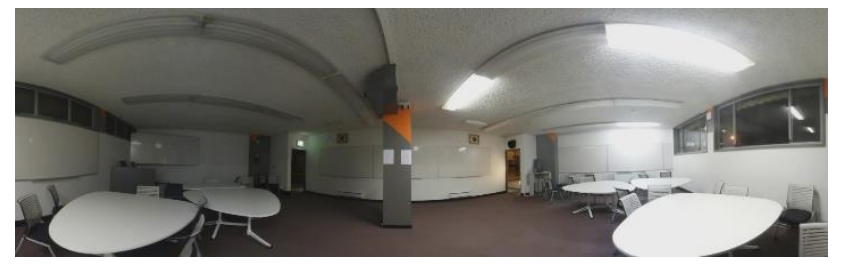

Figure 5. Scenario 1 setup panoramic view

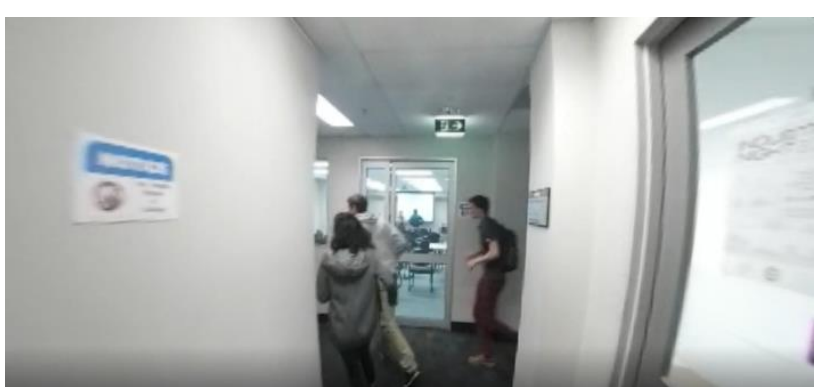

Figure 6. Scenario 2 still shot as viewed through VR gear

Exit signs used in the study, attached to the top of the corridor, adhered to the ISO and AS2293.1 - 2005 for signage size, location, and illumination. The direction of exit signs was changed depending on the scenario to be tested. Left, right, and bi-directional signs were utilised.

\subsection{The Survey Process}

Participants read the explanatory statement for the experiment and signed the ethics form. Once ready, a demo VR video was presented to adjust the focus of the lens. This would reduce errors due to unfamiliarity with using the VR headset. Inside the virtual scenario, the standard fire alarm went off with a whooping sound indicating an evacuation situation. The participants were allowed enough time to analyse their surroundings before the screen went blank and were asked to choose an exit. The responses to questions were conveyed by participants verbally. If any, other individuals involved in the scenario were pre-recorded doing situation-appropriate movements to maintain realism. Participants may not truly perceive the simulated agents as real persons, and realism could be low if not carefully designed. All the scenarios' exit choices were equally valid options, with all possibilities eventually leading up to an exit. Therefore, the focus of scenario design was to observe the participants' preferential behaviour as an effect of influencing factors. 


\subsection{Data Collection}

A questionnaire was prepared for each participant to record the responses. To make sure participants didn't have to take the VR gear off every time they answered a question, response to each case in the scenario was recorded during the blank spaces in the video while participants were still immersed in the environment. In the questionnaire, the case description, participants' choice, and their details were recorded. The case videos were presented in 8 sets of randomised orders to reduce autocorrelation.

\section{ANALYSIS}

Statistical analysis of the data was conducted using the opensource software BIOGEME (Bierlaire, 2020), a discrete choice modelling software. A utility function was estimated to model the effect of factors contributing to the decision-making process based on the experiment results. Discrete choice modelling differs from regression analysis as the choice set has a limited number of mutually exclusive alternatives, exit doors being the choices in this study. The model estimated a probabilistic outcome for the likelihood of exit choice using statistically significant factors. The influencing factors modelled included exit sign direction, HB, level of physical activity involved, obstruction, exit familiarity, etc. The Probabilistic Utility Function was chosen over the deterministic Utility Function because it offers a more realistic model of the situation. It is assumed that the data is incomplete or incorrect regarding all the factors in each scenario. It is also assumed that the questionnaire captures incomplete information about the factors related to the decision-maker as it is also impossible to account for all the individual characteristics of a participant-for example, the tendency to follow people or notice exit signs.

\subsection{Discrete Choice Modelling}

Discrete choice modelling can connect different statistical parameters from an individual's experimental response to the alternatives' or the decision-makers' attributes. This method generates a probability function for exit choice using stochastic assumptions. For further details on DCM, readers can refer to (Ortúzar \& Willumsen, 2011). The discrete choice model variables considered were building familiarity, number of people, and distance from the exits, etc. Given the demographic distribution of the subjects' age and gender came out to be statistically insignificant in the exit choice behaviour and were, therefore, omitted from the report. One of the main reasons for that could be that all the 84 participants were college students and hence belonged to a similar age group.

The exit choice was modelled with the utility axiom assuming that decision-makers select an alternative that they believe has the highest utility. BIOGEME was used to estimate the logit model. The utility function was determined, and the probability of all exit choices was calculated from the utility. The discrete outcome ' $i$ ' with ' $j$ ' alternatives is defined by the utility function. There is a positive correlation between the utility of an alternative and the probability of selecting that alternative compared to other alternatives. The general equation for the utility function is given in equation 1 .

$$
U_{i}=V_{i}+e_{i}
$$

where $U_{\mathrm{i}}=$ total utility of alternative ' $\mathrm{i}$ '

$V_{\mathrm{i}}=$ deterministic component of variable ' $\mathrm{i}$ '

$e_{\mathrm{i}}=$ stochastic component (error term) of ' $\mathrm{i}$ '
The equation for the deterministic component $\left(\mathrm{V}_{\mathrm{i}}\right)$ can be observed in equation 2 :

$$
\mathrm{V}_{i}=\sum_{i=1}^{k} \beta_{i} X_{i}
$$

where $\mathrm{k}=$ number of factors used for utility function

$\beta_{\mathrm{i}}=$ parameter defining weight of factors

$X_{\mathrm{i}}=$ factors for selection

The logit model assumes that the stochastic (error) component is distributed following a Gumbel distribution. If we consider ' $t$ ' as a set of alternatives for the discrete choice model, the probability that a decision-maker will choose the discrete alternative ' $i$ ' over ' $j$ ' other alternatives, it can be determined from the equation:

$$
P_{n i t}=\int \prod_{t} \frac{e^{V_{n i t}}}{\sum_{j} e^{V_{n j t}}} f(\beta) d \beta
$$

where $d \beta=$ vector of utility coefficients

$\mathrm{f}(\beta)=$ probability density function of utility coefficients

4.1.1 Arc Elasticity: The arc elasticity is the ratio of the percentage change in the unit of one the factor to the percentage change of the other variable. For example, by first calculating the probability of an exit choice, and then calculating the probability of the choice by changing the familiarity unit by one unit, while keeping the units of crowd and distance consistent, we can use the following equation to find the arc elasticity of familiarity.

$$
e U_{i}=\delta P\left(U_{i}\right) / \delta\left(U_{i}\right)
$$

where $\mathrm{P}\left(U_{i}\right)=$ change in probability of selection of an exit $\left(U_{i}\right)=$ change in the factor in consideration

The value of arc elasticity demonstrates the significance of one factor in the equation over another in exit choice behaviour.

\section{RESULTS}

The survey collected information from 84 participants in total, and the total number of observations collected was 864 . From a preliminary analysis, most of the participants were from a young age group between 21-29. The average age of participants was 26 , with a standard deviation of 2.1. The gender distribution of the group of participants was $57 \%$ male and $43 \%$ female.

\subsection{Modelling Outcomes}

5.1.1 Scenario 1: Utility functions for scenario 1 derived from equation 2 are given below in equations 5 and 6 . The ASC was normalised for the alternative-specific scenarios.

$$
\begin{aligned}
& U_{1}=A S C_{1}+\beta_{f}\left(\text { famil }_{1}\right)+\beta_{h}\left(\text { herd }_{1}\right)+\beta_{d}\left(\text { dist }_{1}\right) \\
& U_{2}=A S C_{2}+\beta_{f}\left(\text { famil }_{2}\right)+\beta_{h}\left(\text { herd }_{2}\right)+\beta_{d}\left(\text { dist }_{2}\right)
\end{aligned}
$$

where $\mathrm{ASC}_{\mathrm{n}}=$ alternative specific constant

famil $_{\mathrm{n}}=$ familiarity to individual to exit door herd $_{\mathrm{n}}=$ herding (number of pedestrians) at each door dist $_{\mathrm{n}}=$ distance of individual $\mathrm{n}$ from the exit door $\mathrm{i}$ $\beta=$ utility coefficient

The modelling results out of scenario 1 inputs: 


\begin{tabular}{|c|c|c|c|c|}
\hline Variable & Value & $\begin{array}{c}\text { Standard } \\
\text { Error }\end{array}$ & t-test & p-value \\
\hline$\beta_{\mathrm{f}}$ & 2.210 & 0.38 & 5.77 & 0 \\
$\beta_{\mathrm{h}}$ & 0.644 & 0.22 & 2.83 & 0.01 \\
$\beta_{\mathrm{d}}$ & -0.496 & 0.10 & -4.91 & 0 \\
$\mathrm{ASC}_{1}$ & 0 & $*$ & $*$ & $*$ \\
$\mathrm{ASC}_{2}$ & 0.004 & 0.00 & 0.00 & 1.00 \\
\hline
\end{tabular}

Table 4. DCM Results for scenario 1

With 360 total observations used to estimate the model, the final log-likelihood was -93.57 with a Rho-square and Adjusted Rhosquare as 0.242 and 0.209 , respectively. The probability of an individual choosing an exit choice can be determined using the equation:

$$
P\left(U_{i}\right)=U_{i} / \sum_{i=1}^{n} U_{i}
$$

All variables were determined to have a p-value of smaller than 0.05 , suggesting that at a $95 \%$ confidence interval, they have a significant influence on exit choice behaviour. From the model, familiarity with an exit was the most significant influential factor followed by herding behaviour and the exits' distance. This is directly related to the absolute value of the utility coefficient of each of the factors tested. Arc elasticities based on equation 4 are summarised below:

\begin{tabular}{|l|c|}
\hline \multicolumn{1}{|c|}{ Influencing Factor } & Arc Elasticity \\
\hline Familiarity & 0.401 \\
Herding & 0.156 \\
Exit Distance & -0.121 \\
\hline
\end{tabular}

Table 5. Arc elasticity scenario 1

5.1.2 Scenario 2: Utility functions for scenario 2 are summarised below in equations 8 and 9 .

$$
\begin{aligned}
& U_{1}=A S C_{1}+\beta_{s}\left(\operatorname{sign}_{1}\right)+\beta_{c}\left(\operatorname{crowding}_{1}\right) \\
& U_{2}=A S C_{2}+\beta_{s}\left(\operatorname{sign}_{2}\right)+\beta_{c}\left(\operatorname{crowding}_{2}\right)
\end{aligned}
$$

where $\mathrm{ASC}=$ alternative specific constant $\operatorname{sign}_{\mathrm{n}}=$ direction of exit sign crowding $_{n}=$ number of people crowding each door $\beta=$ utility coefficient

The modelling results out of scenario 2 inputs:

\begin{tabular}{|c|c|c|c|c|}
\hline Variable & Value & $\begin{array}{c}\text { Standard } \\
\text { Error }\end{array}$ & t-test & $\mathrm{p}$-value \\
\hline$\beta_{\mathrm{s}}$ & 0.803 & 0.20 & 3.95 & 0 \\
$\beta_{\mathrm{c}}$ & -0.150 & 0.07 & 0.65 & 0.05 \\
$\mathrm{ASC}_{1}$ & 0 & $*$ & $*$ & $*$ \\
$\mathrm{ASC}_{2}$ & $7.5 \mathrm{e}^{-5}$ & 0.00 & 0.00 & 1.00 \\
\hline
\end{tabular}

Table 6. DCM Results for scenario 2

With 264 total observations used to estimate the model, the final log-likelihood was -171.19 with a Rho-square and Adjusted Rho-square as 0.064 and 0.054 , respectively. The probability of an individual choosing a particular exit choice can be determined using equation 7. All variables were determined to have a pvalue of smaller than 0.05 . From the model, the exit sign's direction is the most influential factor followed by exitcrowding. Arc elasticities based on equation 4 are summarised below:

\begin{tabular}{|l|c|}
\hline \multicolumn{1}{|c|}{ Influencing Factor } & Arc Elasticity \\
\hline Exit Sign & 0.19 \\
Crowding & -0.04 \\
\hline
\end{tabular}

Table 7. Arc elasticity scenario 2

5.1.3 Scenario 3: Utility functions for scenario 3 are summarised below in equations 10 and 11 .

$$
\begin{aligned}
& U_{1}=A S C_{1}+\beta_{a}\left(\text { activity }_{1}\right)+\beta_{o}\left(\text { obstacle }_{1}\right) \\
& U_{2}=A S C_{2}+\beta_{a}\left(\text { activity }_{2}\right)+\beta_{o}\left(\text { obstacle }_{2}\right)
\end{aligned}
$$

where $\mathrm{ASC}=$ alternative specific constant activity $_{\mathrm{n}}=$ physical activity involvement in exiting obstacle $_{n}=$ blockage of an exit $\beta=$ utility coefficient

The modelling results out of scenario 2 inputs:

\begin{tabular}{|c|c|c|c|c|}
\hline Variable & Value & $\begin{array}{c}\text { Standard } \\
\text { Error }\end{array}$ & t-test & $\mathrm{p}$-value \\
\hline$\beta_{\mathrm{a}}$ & -1.64 & 0.20 & -7.95 & 0 \\
$\beta_{\mathrm{o}}$ & -0.36 & 0.21 & -0.68 & 0.03 \\
$\mathrm{ASC}_{1}$ & 0 & $*$ & $*$ & $*$ \\
$\mathrm{ASC}_{2}$ & -0.11 & 0.08 & -2.12 & 0.03 \\
\hline
\end{tabular}

Table 8. DCM Results for scenario 3

With 340 total observations used to estimate the model, the final log-likelihood was -122.45 with a Rho-square and Adjusted Rho-square as 0.264 and 0.252 , respectively. All variables were determined to have a p-value of smaller than 0.05 . From the model, physical activity is the most influential factor followed by an obstacle in front of exits. Both these factors negatively influence the choice of an evacuee. Interestingly, $\mathrm{ASC}_{2}$, alternative specific constant for first-floor exit, had a significant negative influence on choice, indicating participants preferred to climb down the stairs rather than climb up. Arc elasticities based on equation 4 are summarised below:

\begin{tabular}{|l|c|}
\hline \multicolumn{1}{|c|}{ Influencing Factor } & Arc Elasticity \\
\hline Activity & -0.33 \\
Obstacle & -0.09 \\
\hline
\end{tabular}

Table 9 . Arc elasticity scenario 3

\section{DISCUSSION}

\subsection{Behavioural Interpretation of Results}

6.1.1 Familiarity vs Herding: The influence of familiarity with exit was significantly higher than crowding in exit choice. The arc elasticity for this case is (arc familiar)/ (arc herding) = $0.401 / 0.156=2.57$. Familiarity with the exit door had a 2.57 times bigger impact on exit choice than herding behaviour when each factor is changed by one unit. This suggests that evacuees are more likely to choose a familiar exit due to the low overhead of routing an escape.

6.1.2 Exit Sign vs Herding: The influence of exit signs direction was significantly more than following a small herd walking towards an exit (arc sign $) /(\operatorname{arc}$ crowding $)=0.19 / 0.04=$ 4.47. This implies that the impact of exit signs' directions was almost five times than that of a small crowd blocking an exit when each factor is changed by one unit. 
6.1.3 Activity vs Blockage: Physical activity like climbing stairs significantly higher negative affinity than walking around an obstacle in front of an exit (arc activity)/ (arc obstacle) = $0.33 /-0.09=3.79$. This implies that evacuees are more than three times likely to walk around an obstacle than climbing a flight of stairs.

\subsection{Comparison with Previous Experiments}

The experiment results indicate that exit familiarity, $\mathrm{HB}$, activity involvement, and exit signs significantly influence exit choice. An experiment to test the exit familiarity behaviour and construct a familiarity model was conducted in 1999 by (Benthorn \& Frantzich, 1999). Participants mostly chose the usual exit when presented with a choice between the usual exit and emergency exit. Even doubling the distance from the usual exit didn't change the result. When asked about their motivations, subjects were unable to respond, signifying that people are unaware of their instinctive behaviours. In analysing a fire of a 36-story Cook County Administration Building, Chicago, IL, USA, (Proulx, 2001) suggested that people evacuated from familiar exits because people are unprepared to try an unknown route during an emergency, which concurs with the first scenario of this study. (Sime, 1983) familiarity model also indicates that people are more attracted to a familiar exit. A field experiment conducted by (Benthorn \& Frantzich, 1999) at an IKEA warehouse confirms a positive impact of exit familiarity on exit choice. (Bode \& Codling, 2013) suggested that the size and position of exit-signs has an impact on the exit choice.

\subsection{Limitations}

VR was utilised in the study to control the variables within the experiment and provide a safe environment that resembles a field experiment. This method, however, offers some limitations to the experiment. Factors like VR headset latency, screen resolution, voice-over instructions, etc. may have interrupted the immersive experience and altered responses to the questions. Furthermore, consecutive run through the scenarios could cause decision fatigue.

Moreover, the videos used were a simple depiction of real scenarios during an emergency using VR. This has the potential to reduce the social influence of the threshold model (Blascovich, et al., 2002). The lower view angle of the Samsung apparatus used had a fisheye effect on the participant, which slightly varied their depth and distance perception. In the exit familiarity scenario, the familiarising videos were played right before the survey began, which meant that only short-term memory familiarisation could be tested. For a more realistic result on long-term familiarisation, further study would be required. The study's demographic diversity could have limited the results, as most of them were college students. In crowding and herding situations, only up to 3 other people were used in each case. From the literature, it is known that these factors can't be extrapolated linearly as behaviour at high concentration varies significantly. Despite these limitations, VR has proved to be an efficient tool for experimentation and produced similar results to that of a field experiment.

\section{CONCLUSION}

The impact that various factors have on an individual's exit choice was examined in this study. An experiment was performed, which tested various decision-making factors through three different scenarios; building familiarity, HB, obstacles, distance, etc. The analysis utilised VR to capture three scenarios with various cases to test different factors affecting choice. The responses from 86 participants were documented and modelled using Discrete Choice Modelling to determine the significance of each factor on the choice. The significance of each variable on the exit choice was determined by calculating the function's arc elasticity.

Before the experiment, various hypotheses were synthesised about the decision-making process. Furthermore, correlations of various factors with the exit choice utility were also hypothesised. The study demonstrates that the exit choice influencing factors can be quantified into RUMs. The use of VR technology demonstrated a high potential for an in-depth study of human behaviour during emergencies. The equations produced by the models concur with literature from previous research, though the accuracy of predictions remained untested due to project constraints. VR provided an ethical means of recreating real-life emergency conditions and improved reliability of results over questionnaire-based surveys. A further detailed study is required to test multivariable correlations in complex scenarios and test the accuracy of the outcomes of RUMs.

\section{REFERENCE}

Ben-Akiva, M. E., \& Lerman, S. R. (1985). Discrete choice analysis: theory and application to travel demand. MIT Press.

Bierlaire, M. (2020). A short introduction to PandasBiogeme, Version 3.2.6. Transport and Mobility Laboratory, ENAC, EPFL. biogeme.epfl.ch (5 January 2020)

Benthorn, L., \& Frantzich, H. (1999). Fire alarm in a public building: how do people evaluate information and choose evacuation exit? Fire and Materials, 23(6), 311-315.

Bhatt, G. (2004). Bringing virtual reality for commercial Web sites. International Journal of Human-Computer Studies, 60(1), 1-15. https://doi.org/10.1016/j.ijhcs.2003.07.002

Blascovich, J., Loomis, J., Beall, A.C., Swinth, K.R., Hoyt, C.L., \& Bailenson, J.N. (2002). Immersive Virtual Environment Technology as a Methodological Tool for Social Psychology. Psychological Inquiry, 13(2), 103-124.

Bode, N., \& Codling, E.A. (2013). Human exit route choice in virtual crowd evacuations. Animal Behaviour, 86(2), 347-358. https://doi.org/10.1016/j.anbehav.2013.05.025

Cialdini, R. B. (1993). Influence: science and practice (3rd ed.). Harper Collins College Publishers.

Darley, J. M., \& Latane, B. (1968). Bystander intervention in emergencies: diffusion of responsibility. Journal of Personality and Social Psychology, 8(4p1), 377-383. https://doi.org/10.1037/h0025589

Dell'Olio, L., Ibeas, A., \& Cecin, P. (2011). Quality of service desired by public transport users. Transport Policy, 18(1), 217227. https://doi.org/10.1016/j.tranpol.2010.08.005

Fahy, R.F., Proulx, G., \& Aiman, L. (2012). Panic or not in fire: Clarifying the misconception. Fire and Materials, 36(5-6), 328338. https://doi.org/10.1002/fam.1083 
Gamberini, L., Cottone, P., Spagnolli, A, Varotto, D, \& Mantovani, G. (2010). Responding to a fire emergency in a virtual environment: different patterns of action for different situations. $\quad$ Ergonomics, $46(8), \quad 842-858$. https://doi.org/10.1080/0014013031000111266

Greene, W. H. (2000). Econometric analysis. Pearson Education.

Gwynne, S, Galea, E.R, Owen, M, Lawrence, P.J, \& Filippidis, L. (1999). A review of the methodologies used in the computer simulation of evacuation from the built environment. Building $\begin{array}{lll}\text { and } \quad \text { Environment, 34(6), } & \text { 741-749. }\end{array}$ https://doi.org/10.1016/s0360-1323(98)00057-2

Haghani, M., \& Sarvi, M. (2017). How perception of peer behaviour influences escape decision making: The role of individual differences. Journal of Environmental Psychology, 51,141-157. https://doi.org/10.1016/j.jenvp.2017.03.013

Helbing, D, Johansson, A, \& Al-Abideen, H. (2007). Dynamics of crowd disasters: An empirical study. Physical Review. E, Statistical, Nonlinear, and Soft Matter Physics, 75(4), 046109. https://doi.org/10.1103/physreve.75.046109

Heliövaara, S, Kuusinen, J, Rinne, T, Korhonen, T, \& Ehtamo, H. (2012). Pedestrian behavior and exit selection in evacuation of a corridor - An experimental study. Safety Science, 50(2), 221-227. https://doi.org/10.1016/j.ssci.2011.08.020

Hoogendoorn, S.P, \& Bovy, P.H.L. (2004). Pedestrian routechoice and activity scheduling theory and models. Transportation Research. Part B: Methodological, 38(2), 169190. https://doi.org/10.1016/s0191-2615(03)00007-9

Kinateder, M, Müller, M, Jost, M, Mühlberger, A, \& Pauli, P. (2014). Social influence in a virtual tunnel fire - Influence of conflicting information on evacuation behavior. Applied Ergonomics, $\quad 45(6)$, 1649-1659. https://doi.org/10.1016/j.apergo.2014.05.014

Kuligowski, E, Peacock, R, Hoskins, B. (2010). A Review of Building Evacuation Models, 2nd Ed, NIST Technical Note 1680.

Lovreglio, R, Borri, D, dell'Olio, L, \& Ibeas, A. (2014). A discrete choice model based on random utilities for exit choice in emergency evacuations. Safety Science, 62, 418426. https://doi.org/10.1016/j.ssci.2013.10.004

Lovreglio, R, Fonzone, A, Dell'Olio, L, Borri, D, Ibeas, A. (2014). The Role of Herding Behaviour in Exit Choice During Evacuation. Procedia - Social and Behavioral Sc. 160. 390-399.

Lovreglio, R, Ronchi, E, \& Nilsson, D. (2015). A model of the decision-making process during pre-evacuation. Fire Safety Journal, 78 $168-179$ https://doi.org/10.1016/j.firesaf.2015.07.001

Lovreglio, R, Ronchi, E, \& Nilsson, D. (2016). An Evacuation Decision Model based on perceived risk, social influence and behavioural uncertainty. Simulation Modelling Practice and Theory, 66, 226-242. https://doi.org/10.1016/j.simpat.2016.03.006

Moussaïd, M, Kapadia, M, Thrash, T, Sumner, R.W, Gross, M, Helbing, D, \& Hölscher, C. (2016). Crowd behaviour during high-stress evacuations in an immersive virtual environment.
Journal of the Royal Society Interface, 13(122), 20160414. https://doi.org/10.1098/rsif.2016.0414

Nilsson, D, \& Johansson, A. (2009). Social influence during the initial phase of a fire evacuation-Analysis of evacuation experiments in a cinema theatre. Fire Safety Journal, 44(1), 7179. https://doi.org/10.1016/j.firesaf.2008.03.008

Olander, J, Ronchi, E, Lovreglio, R, \& Nilsson, D. (2017). Dissuasive exit signage for building fire evacuation. Applied $\left.\begin{array}{lllll}\text { Ergonomics, } & 59 & (P t & A\end{array}\right), \quad 84-93$. https://doi.org/10.1016/j.apergo.2016.08.029

Olivier, A, Bruneau, J, Cirio, G, Pettre, J. (2014). A Virtual Reality Platform to Study Crowd Behaviors. Transportation Research Procedia. 2. 114-122. 10.1016/j.trpro.2014.09.015.

Ortuİzar S., Ortúzar S., \& Willumsen. (2011). Modelling transport (4th ed.). Wiley-Blackwell.

Proulx, G. (2001). Occupant behaviour and evacuation. International Fire Protection Symposium, 219-223. Munich: Institute for Research in Construction.

Rauterberg, M. (2004). Positive effects of VR Technology on Human Behaviour. International Conference on Artificial Reality and Telexistence, 85-88. ICAT.

Riva, G, Mantovani, F, Capideville, C.S, Preziosa, A, Morganti, F, Villani, D, Gaggioli, A, Botella, C, \& Alcañiz, M. (2007). Affective Interactions Using Virtual Reality: The Link between Presence and Emotions. Cyberpsychology \& Behavior, 10(1), 45-56. https://doi.org/10.1089/cpb.2006.9993

Ronchi, E, Nilsson, D, \& Gwynne, S M. V. (2012). Modelling the Impact of Emergency Exit Signs in Tunnels. Fire Technology, 48(4), 961-988. https://doi.org/10.1007/ s10694-012-0256-y

Sime, J. D. (1985). Movement toward the Familiar. Environment and Behavior, 17(6), 697-724. https://doi.org/10.1177/0013916585176003

Sime, J. D. (1983). Affiliative behaviour during escape to building exits. Journal of Environmental Psychology, 3(1), 2141. https://doi.org/10.1016/s0272-4944(83)80019-x

Tong, D., \& Canter, D. (1985). The decision to evacuate: a study of the motivations which contribute to evacuation in the event of fire. Fire Safety Journal, 9, 257-265.

Ziemer, Christine J, Plumert, Jodie M, Cremer, James F, \& Kearney, Joseph K. (2009). Estimating distance in real and virtual environments: Does order make a difference? Attention, Perception, \& Psychophysics, 71(5), 1095-1106. https://doi.org/10.3758/APP.71.5.1096 